Article

\title{
Atomic Structure, Electronic and Mechanical Properties of Pyrophyllite under Pressure: A First-Principles Study
}

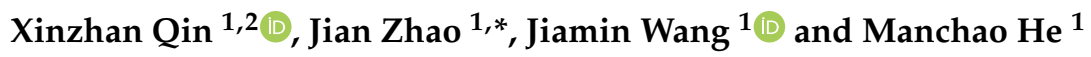 \\ 1 State Key Laboratory of Geomechanics and Deep Underground Engineering, China University of Mining \\ and Technology, Beijing 100083, China; xinzhanqin@gmail.com (X.Q.); jasmin1029@163.com (J.W.); \\ manchaohecumtb@163.com (M.H.) \\ 2 School of Civil, Environmental and Mining Engineering, the University of Adelaide, Adelaide 5005, Australia \\ * Correspondence: zhaojian@cumtb.edu.cn; Tel.: +86-1521-056-7994
}

Received: 26 July 2020; Accepted: 31 August 2020; Published: 1 September 2020

\begin{abstract}
Pyrophyllite is extensively used in the high-pressure synthesis industry as a pressure-transmitting medium because of its outstanding pressure transmission, machinability, and insulation. Therefore, the atomic structure, electronic, and mechanical behavior of pyrophyllite $\left[\mathrm{Al}_{4} \mathrm{Si}_{8} \mathrm{O}_{20}(\mathrm{OH})_{4}\right]$ under high pressure should be discussed deeply and systematically. In the present paper, the lattice parameters, bond length, the electronic density of states, band structure, elastic constants, and mechanical parameters of pyrophyllite are investigated using density functional theory (DFT) from a microscopic perspective. The pressure dependence of atomic structure, electronic, and mechanical properties of pyrophyllite is analyzed for a wide range of pressure (from 0 GPa to 13.87 GPa). Under high pressure, the major bond lengths and layer thicknesses decrease slightly, and mechanical properties are improved with increasing pressure. The calculated electronic and band structures show only a slight change with increasing pressure, implying that the effect of pressure on the electronic property of pyrophyllite is weak, and pyrophyllite still has good stability under high pressure. The theoretical calculations presented here clarify the electronic and mechanical properties of natural pyrophyllite that are difficult to obtain experimentally because of their small particle size.
\end{abstract}

Keywords: pyrophyllite; first-principles calculations; mechanical properties; atomic structure; electronic property

\section{Introduction}

Pyrophyllite $\left[\mathrm{Al}_{2} \mathrm{Si}_{4} \mathrm{O}_{10}(\mathrm{OH})_{2}\right]$ is an important non-metallic material commonly used in metallurgy, construction materials, petroleum, chemical and light industry, and other fields because of its good physico-chemical and mechanical characteristics [1]. It is generally known that pyrophyllite is a kind of hydrous aluminosilicate mineral with continuous layered structure. The water is distributed between two silica tetrahedral layers [2], and is linked with aluminum to form an "aluminum hydroxide" layer- $\left[\mathrm{Al}(\mathrm{OH})_{3}\right]$ [3]. The structural lamellae mainly depend on van der Waals force, and it is easy to slip under the shear action, so it is an ideal pressure-transmission medium. In addition, the compact lamellar structure gives pyrophyllite good sealing performance [4]. As a result, pyrophyllite has been widely used in the high-pressure synthesis industry as a sealed pressure-transmission medium. High-pressure synchrotron radiation X-ray diffraction experiment on pyrophyllite powder showed that the ultimate pressure of pyrophyllite as a pressure medium should be less than $15 \mathrm{GPa}$. Deng et al. [5] indicated that the layered and ordered stacking structure of pyrophyllite is destroyed by high-pressure sliding shear after $15 \mathrm{GPa}$ high-pressure, and it is transformed into a disorderly stacked-unit lamellar 
structure. Therefore, understanding the electronic and mechanical properties of pyrophyllite under pressures is one main topics for researchers in the fields of geophysics and geomechanics $[6,7]$. A series of experimental studies have discussed the structure and elastic modulus of pyrophyllite under pressure. Sachse et al. [8] studied the influence of preloading stress (from 0.5 GPa to 4.0 GPa) on the elastic constant and elastic wave velocity of pyrophyllite by using the ultrasonic method. Zhang et al. [9] conducted nanoindentation experiments to investigate the elasticity normal to the basal plane of the pyrophyllite. The Young's modulus and surface charge density of pyrophyllite were obtained in the experiment. Cheng et al. [10] obtained the effects of anisotropy on the compressive strength, wave velocity, static modulus, and dynamic modulus of pyrophyllite core by using ultrasonic transmission technique and uniaxial compression tests. The orientation of uniaxial compressive strength and Young's modulus of pyrophyllite were given in detail. Jeremie et al. [7] proposed a hybrid experimental modeling approach, which combined nanoindentation in orthogonal directions with analytical derivations of the cohesive energy, to predict the macroscopic mechanical performance of pyrophyllite.

All the above results were obtained by different experimental methods, which were helpful to understand the atomic structure and mechanical properties of pyrophyllite under pressure; however, these characteristics of pyrophyllite were still difficult to measure directly and precisely due to the small grain of pyrophyllite and the limitation of the experimental methods. The theoretical analysis of the atomic structure, electronic, and mechanical properties of clay minerals from a microscopic point of view will help to solve engineering problems [11-13]. The first principle calculation method based on functional theory (DFT) has been proved to be a powerful and reliable tool to study the atomic structure, mechanics and electronic properties of crystal at the molecular level [14-16]. Bridgeman [17] first investigated the atomic structure of pyrophyllite using the DFT plane-wave pseudopotential method. In 2003, Refson et al. [18] calculated the lattice parameters and ion positions of pyrophyllite, and further analyzed the distortion characteristics of pyrophyllite crystal layer. Katti et al. [19] applied different stresses (from $0 \mathrm{GPa}$ to $1.65 \mathrm{GPa}$ ) perpendicular to the $a-b$ plane of pyrophyllite crystal. The results showed that the vertical deformation of pyrophyllite was mainly due to the decrease of layer spacing. Militzer et al. [20] indicated that GGA tends to underbind the sheets by comparing the lattice constant and elastic constant of the sheet silicates derived with different functionals, which will affect the accuracy of the predicted constants. After a series of structural optimization calculations, we choose local-density approximation (LDA) functional in the present paper.

The above results were in line with the experimental results, but the research on the electrical and mechanical properties of pyrophyllite under high pressure was quite limited. In the present work, the effect of pressure on pyrophyllite is studied by calculating the lattice parameter, bonding length, charge density, density of states, the elastic constants, elastic modulus, wave velocity and Poisson ratio of pyrophyllite within a certain pressure range (from $0 \mathrm{GPa}$ to $13.87 \mathrm{GPa}$ ). In general, the atomic scale information obtained in the present work provides a theoretical basis for the mechanical behavior of pyrophyllite under high pressures.

\section{Materials and Methods}

The calculations for pyrophyllite are based on density functional theory (DFT) within the LDA [21] as implemented in the Vienna ab-initio simulation package (VASP) [22] code through the use of the projector augmented wave (PAW) pseudopotentials [23]. All atomic positions are relaxed according to the calculated Helmann-Feynman forces. The energy cut off for the plane-wave basis is set at $600 \mathrm{eV}$. The $9 \times 5 \times 5$ Monkhorst-Pack [24] $k$-point set is used to sample the Brillouin zone. In our calculation, the valence electrons include $1 s^{1}$ of $\mathrm{H}, 2 s^{2}$ and $2 p^{4}$ of $\mathrm{O}, 3 s^{2}$ and $3 p^{1}$ of $\mathrm{Al}, 3 s^{2}$ and $3 p^{2}$ electrons of $\mathrm{Si}$. The optimization of atomic geometries is performed via a conjugate-gradient algorithm until residual force acting on atoms is less than $0.01 \mathrm{eVA}^{-1}$.

Elastic properties represent the deformation extent of the material under the applied stress [25], which are the inherent property of the material itself [26-28]. To better understand the effect of applied 
pressure on the mechanical properties, we systematically study the elastic properties of pyrophyllite based on density functional theory, including elastic modulus such as the orientation-averaged bulk, shear, and Young's moduli, as well as the Poisson's ratios.

The crystal is generally considered to be a homogeneous continuous media when discussing the elastic properties. According to the principle of continuum mechanics, when the material is within the elastic limit, the stress and strain of the material satisfies the generalized Hooke's law. Under the condition of elastic limit and small strain, the linear relationship between stress and strain can be expressed as a single coordinate matrix:

$$
\left|\begin{array}{l}
\sigma_{1} \\
\sigma_{2} \\
\sigma_{3} \\
\sigma_{4} \\
\sigma_{5} \\
\sigma_{6}
\end{array}\right|=\left|\begin{array}{llllll}
C_{11} & C_{12} & C_{13} & C_{14} & C_{15} & C_{16} \\
C_{21} & C_{22} & C_{23} & C_{24} & C_{25} & C_{26} \\
C_{31} & C_{32} & C_{33} & C_{34} & C_{35} & C_{36} \\
C_{41} & C_{42} & C_{43} & C_{44} & C_{45} & C_{46} \\
C_{51} & C_{52} & C_{53} & C_{54} & C_{55} & C_{56} \\
C_{61} & C_{62} & C_{63} & C_{64} & C_{65} & C_{66}
\end{array}\right| *\left|\begin{array}{l}
\varepsilon_{1} \\
\varepsilon_{2} \\
\varepsilon_{3} \\
\varepsilon_{4} \\
\varepsilon_{5} \\
\varepsilon_{6}
\end{array}\right|
$$

$C_{i j}$ is called the elastic stiffness coefficient, i.e., the elastic constant.

Pyrophyllite crystal belongs to triclinic system with 21 independent elastic constants. After applying strain, the change of strain energy can be expressed as:

$$
\Delta \mathrm{E}=\frac{\mathrm{V}}{2} \sum_{i=1}^{6} \sum_{j=1}^{6} \mathrm{C}_{i j} \mathrm{e}_{i} \mathrm{e}_{j}
$$

Using the above relationship, the elastic constant matrix $C_{i j}$ can be derived from the change in the total energy of the crystal by applying a small strain to the equilibrium structure. It can not only reflect the mechanical properties of the material, but also be used to estimate the response stiffness of the material system to the external environment by strain $\varepsilon$, which determines the response of the crystal to external stress and the ability to resist deformation with applied stress.

If the stress component is used to represent the strain component, it can be expressed as:

$$
\varepsilon_{i}=\mathrm{S}_{i j} \sigma_{j}(i, j=1,2, \cdots, 6)
$$

$S_{i j}$ is called the flexibility coefficient.

After determining the flexibility coefficient of the material, the Young's modulus $\left(E_{i}\right)$ and Poisson's ratio $\left(v_{i j}\right)$ in three directions along the orthogonal coordinate system can be calculated from the flexibility coefficient $\left(S_{i j}\right)$ :

$$
\begin{gathered}
E_{i}=S_{i i}^{-1} \quad(i, j=1,2,3) \\
v_{i j}=-\frac{\varepsilon_{i i}}{\varepsilon_{j j}}=-\frac{S_{i j}}{S_{j j}} \quad(i, j=1,2,3, i \neq j)
\end{gathered}
$$

In terms of theoretical calculation of the elastic modulus, Voigt [29] assumed that each component has the same strain, equal to the average strain of the polycrystal, and the bulk modulus $\left(B_{V}\right)$ and shear modulus $\left(G_{V}\right)$ of the polycrystal could be expressed by the single crystal stiffness coefficient $\left(C_{i j}\right)$ :

$$
\begin{gathered}
B_{V}=\frac{\left(C_{11}+C_{22}+C_{33}\right)+2\left(C_{12}+C_{13}+C_{23}\right)}{9} \\
G_{V}=\frac{\left(C_{11}+C_{22}+C_{33}\right)-\left(C_{12}+C_{13}+C_{23}\right)+3\left(C_{44}+C_{55}+C_{66}\right)}{15}
\end{gathered}
$$


Reuss [30] assumed that the stresses of the components were the same, equal to the average stress of the polycrystal, and the bulk modulus $\left(B_{R}\right)$ and shear modulus $\left(G_{R}\right)$ of the polycrystal were expressed by the single crystal compliance coefficient $\left(S_{j j}\right)$ :

$$
\begin{gathered}
B_{R}=\frac{1}{\left(S_{11}+S_{22}+S_{33}\right)+2\left(S_{12}+S_{13}+S_{23}\right)} \\
G_{R}=\frac{15}{4\left(S_{11}+S_{22}+S_{33}\right)-4\left(S_{12}+S_{13}+S_{23}\right)+3\left(S_{44}+S_{55}+S_{66}\right)}
\end{gathered}
$$

Hill [31] used the elastic limit principle to prove that the Voigt and Reuss models respectively gave the upper and lower limits of the polycrystalline average elastic modulus, and proposed the arithmetic mean of the Voigt and Reuss models as the average elastic modulus of the polycrystal, namely Voigt-Reuss-Hill approximation:

$$
\begin{aligned}
B_{H} & =\frac{\left(B_{V}+B_{R}\right)}{2} \\
G_{H} & =\frac{\left(G_{V}+G_{R}\right)}{2}
\end{aligned}
$$

Furthermore, the Young's modulus $(E)$ and Poisson's ratio $(v)$ of the polycrystal can be obtained from the bulk modulus $(B)$ and the shear modulus $(G)$ :

$$
\begin{gathered}
E=\frac{9 B G}{3 B+G} \\
v=\frac{3 B-2 G}{2(3 B+G)}
\end{gathered}
$$

The elastic wave velocity of clay minerals is of great significance for studying the internal structure and properties of pyrophyllite. Compression wave velocity $\left(V_{p}\right)$ and shear wave velocity $\left(V_{s}\right)$ can be expressed by bulk modulus $(B)$, shear modulus $(G)$ and density $(\rho)$ :

$$
\begin{gathered}
V_{p}=\sqrt{\frac{3 B+4 G}{3 \rho}} \\
V_{s}=\sqrt{\frac{G}{\rho}}
\end{gathered}
$$

\section{Results and Discussions}

Pyrophyllite is a planar 2:1 phyllosilicate composed of two-dimensional mineral layers that stack into particles [32]. The 2:1 layers of phyllosilicate are holding together mainly by weak van der Waals forces [33]. Each layer consists of an octahedral sheet sandwiched between two opposing tetrahedral sheets (see in Figure 1). Pyrophyllite with an ideal structural formula of $\mathrm{Al}_{2} \mathrm{Si}_{4} \mathrm{O}_{10}(\mathrm{OH})_{2}$ belongs to the $\mathrm{C}^{\overline{1}}$ space group [34]. In the present paper, a $1 \times 1 \times 1$-unit cell of pyrophyllite $\left[\mathrm{Al}_{4} \mathrm{Si}_{8} \mathrm{O}_{20}(\mathrm{OH})_{4}\right]$ was used to calculate the electronic and mechanical properties. The unit cell consists of 40 atoms including four $\mathrm{Al}$ atoms, eight $\mathrm{Si}$ atoms, four $\mathrm{H}$ atoms, and $24 \mathrm{O}$ atoms, as shown in Figure 1. The unit crystal layer is a piece of aluminum oxide octahedron $\left[\mathrm{AlO}_{4}(\mathrm{OH})_{2}\right]$ in the middle of two pieces of silicon tetrahedron $\left(\mathrm{SiO}_{4}\right)$ [35], and the apical oxygen $\left(\mathrm{O}_{a}\right)$ of the silicon oxide tetrahedral is linked to $\mathrm{Al}$ in aluminum oxide octahedron. Only two thirds of the central positions of the aluminum oxide octahedrons are occupied by $\mathrm{Al}$. The oxygen connected with the internal $\mathrm{H}$ and $\mathrm{Al}$ is called internal oxygen $\left(\mathrm{O}_{i}\right)$; and the oxygen that made up the silicate ring system of the silicon oxide tetrahedral is called ring oxygen $\left(\mathrm{O}_{r}\right)$ [36-38]. The calculated structural parameters in the present paper are 
$a=5.180 \AA, b=8.970 \AA, c=9.950 \AA, \alpha=90.00^{\circ}, \beta=99.50^{\circ}$, and $\gamma=90.00^{\circ}$, as shown in Table 1 , and the results are in good accord with available experimental data [39].

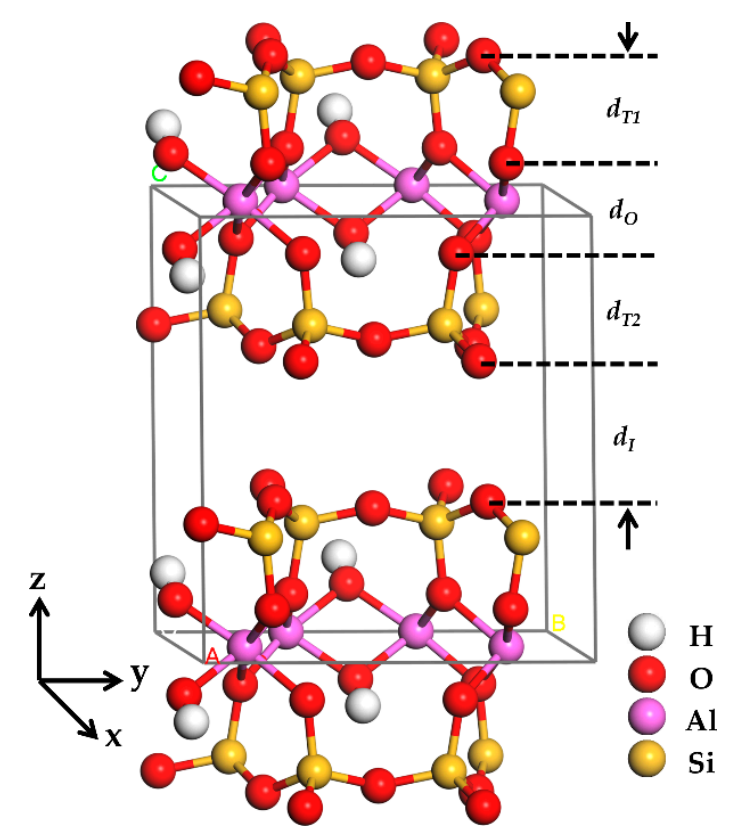

Figure 1. Unit cell of pyrophyllite $\left[\mathrm{Al}_{4} \mathrm{Si}_{8} \mathrm{O}_{20}(\mathrm{OH})_{4}\right]$ containing 40 atoms. $\boldsymbol{d}_{\boldsymbol{T} 1}$ and $\boldsymbol{d}_{\boldsymbol{T} 2}$-layer thickness of silicon oxide tetrahedral sheet; $d_{O}$-layer thickness of aluminum oxide octahedral sheet; $\boldsymbol{d}_{\boldsymbol{I}}$-interlayer thickness of two-dimensional layer.

Table 1. Compared with experimental values, the calculated lattice parameters and volume of pyrophyllite $\left[\mathrm{Al}_{4} \mathrm{Si}_{8} \mathrm{O}_{20}(\mathrm{OH})_{4}\right]$ using basis sets in this work.

\begin{tabular}{cccc}
\hline Parameters & Experiment [39] & This Work & Difference \\
\hline$a$ & $5.160 \AA$ & $5.180 \AA$ & $0.387 \%$ \\
$b$ & $8.966 \AA$ & $8.970 \AA$ & $0.414 \%$ \\
$c$ & $9.347 \AA$ & $9.950 \AA$ & $6.451 \%$ \\
$\alpha$ & $91.18^{\circ}$ & $90.00^{\circ}$ & $-1.129 \%$ \\
$\beta$ & $100.46^{\circ}$ & $99.50^{\circ}$ & $-0.955 \%$ \\
$\gamma$ & $89.64^{\circ}$ & $90.00^{\circ}$ & $0.401 \%$ \\
$V$ & $425.16 \AA^{3}$ & $437.13 \AA^{3}$ & $2.815 \%$ \\
\hline
\end{tabular}

The electronic and mechanical properties of pyrophyllite at extreme operating conditions are very crucial in engineering application. To further understand the atomic structure, electronic, and mechanical properties of the pyrophyllite, the pressure dependence of these properties for pyrophyllite are studied. To avoid Pulay stress problems, the geometric optimization of each pressure state is performed at a fixed volume rather than at a constant pressure. We calculate the total energy $(E)$ of pyrophyllite at a series of volumes as $\mathrm{V}_{0}, 0.98 \mathrm{~V}_{0}, 0.96 \mathrm{~V}_{0}, 0.94 \mathrm{~V}_{0}, 0.92 \mathrm{~V}_{0}, 0.9 \mathrm{~V}_{0}, 0.88 \mathrm{~V}_{0}$, $0.86 \mathrm{~V}_{0}, 0.84 \mathrm{~V}_{0}, 0.82 \mathrm{~V}_{0}, 0.8 \mathrm{~V}_{0}$ (where $\mathrm{V}_{0}$ is the equilibrium volume at $0 \mathrm{GPa}$ ) and deduce the $P-\mathrm{V}$ relation by the thermodynamic derivative $P=-\Delta E / \Delta \mathrm{V}$. With the decrease of volume, the total energy of pyrophyllite and thermodynamic derivative pressure increase gradually (see in Figure 2). 


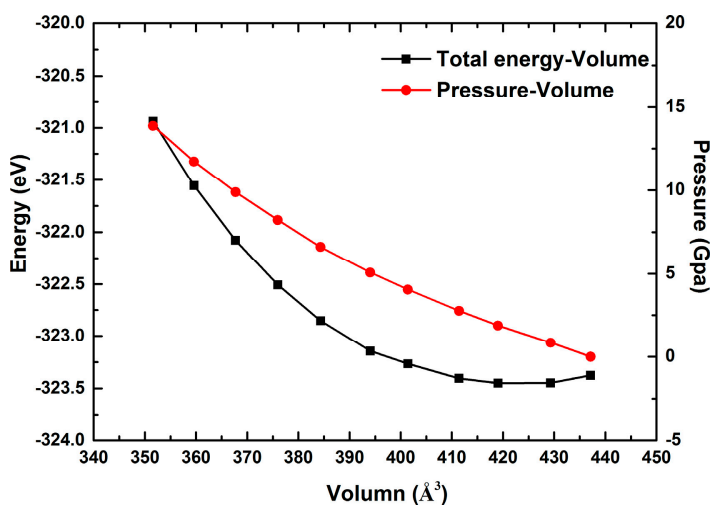

Figure 2. The relationship between total energy-volume $(E-V)$ and pressure-volume $(P-V)$ of pyrophyllite $\left[\mathrm{Al}_{4} \mathrm{Si}_{8} \mathrm{O}_{20}(\mathrm{OH})_{4}\right]$. The black solid square was the first round of calculation $E$, and then $P$ could be derived from the relation $P=-\Delta E / \Delta V$.

\subsection{Effect of Pressure on the Atomic Structure of Pyrophyllite}

To understand the electronic and mechanical properties of the pyrophyllite, the effect of the atomic structure is investigated. Different hydrostatic pressures (from 0 GPa to $13.87 \mathrm{GPa}$ ) are applied to the optimized pyrophyllite crystal, and the curves of the volume and intrinsic energy with pressure are obtained as shown in Figure 2. The results show that the pressure is inversely proportional to the volume change. It is obvious that there is a negative correlation between the volume value and the pressure value of pyrophyllite.

For further analyzing the effect of pressure on the atomic structure of pyrophyllite, different bond lengths under given pressures are listed in Table 2 . The calculated values at $0 \mathrm{GPa}$ are in good agreement with the experimental data [39]. It is obvious that with increasing the pressure, the bond lengths of the $\mathrm{Si}-\mathrm{O}_{a}, \mathrm{Si}-\mathrm{O}_{r}, \mathrm{Al}-\mathrm{O}_{a}$, and $\mathrm{Al}-\mathrm{O}_{i}$ are decreased. Under different pressure, we find that the $\mathrm{Si}-\mathrm{O}_{a}$ bonds linked to the octahedral aluminum had longer length than the other $\mathrm{Si}-\mathrm{O}_{r}$ bonds not linked to the octahedral aluminum. Similarly, the $\mathrm{Al}-\mathrm{O}_{a}$ bonds connected with the tetrahedral silicon have longer length than the $\mathrm{Al}-\mathrm{O}_{i}$ bonds length. These results show that the cation-anion bond along the $c$-axis in pyrophyllite is weaker than the cation-anion bond along the $a-b$ plane, which partly explained why the large lattice deformation observed in pyrophyllite always along the $c$-axis.

Table 2. Compared with experimental values, the calculated average bond lengths in optimized structure of pyrophyllite $\left[\mathrm{Al}_{4} \mathrm{Si}_{8} \mathrm{O}_{20}(\mathrm{OH})_{4}\right]$ at $0 \mathrm{GPa}$ and that of given pressures.

\begin{tabular}{|c|c|c|c|c|c|c|c|c|c|c|c|c|}
\hline \multirow{2}{*}{$\begin{array}{l}\text { Pressure } \\
\text { (GPa) }\end{array}$} & \multirow{2}{*}{$\begin{array}{c}\text { Experiment [39] } \\
0.00\end{array}$} & \multicolumn{11}{|c|}{ This Work } \\
\hline & & 0.00 & 0.85 & 1.88 & 2.77 & 4.05 & 5.07 & 6.62 & 8.23 & 9.89 & 11.73 & 13.87 \\
\hline $\mathrm{Si}-\mathrm{O}_{a}(\AA)$ & 1.633 & 1.632 & 1.631 & 1.630 & 1.629 & 1.628 & 1.627 & 1.626 & 1.625 & 1.625 & 1.622 & 1.622 \\
\hline $\mathrm{Si}-\mathrm{O}_{r}(\AA)$ & 1.612 & 1.613 & 1.612 & 1.611 & 1.610 & 1.609 & 1.609 & 1.608 & 1.607 & 1.606 & 1.602 & 1.600 \\
\hline $\mathrm{Al}-\mathrm{O}_{a}(\AA)$ & 1.924 & 1.914 & 1.910 & 1.903 & 1.898 & 1.892 & 1.889 & 1.884 & 1.880 & 1.875 & 1.875 & 1.873 \\
\hline $\mathrm{Al}-\mathrm{O}_{i}(\AA)$ & 1.889 & 1.885 & 1.879 & 1.871 & 1.865 & 1.858 & 1.852 & 1.844 & 1.838 & 1.832 & 1.832 & 1.828 \\
\hline
\end{tabular}

Furthermore, the layer thickness and interlayer thickness of pyrophyllite under different pressures are listed in Table 3. The $d_{T 1}$ and $d_{T 2}$ represent the layer thickness of silicon oxide tetrahedral sheet, the $d_{O}$ represent the layer thickness of aluminum oxide octahedral sheet, and $d_{I}$ represent the interlayer thickness of the two-dimensional layer. As listed in Table 3, the layer thickness of $d_{T 1}, d_{T 2}$, and $d_{O}$ have little varied with increasing the pressure, while the interlayer thickness $d_{I}$ decrease obviously with the increasing pressure from $0 \mathrm{GPa}$ to $13.87 \mathrm{GPa}$. Meanwhile, the layer thickness of octahedral layer of pyrophyllite is bigger than that of tetrahedral layer, and the interlayer spacing is always bigger than the other layer thickness under different pressure. The results reflect that the compression resistance of silicon oxide tetrahedral sheet is stronger than the aluminum oxide octahedral sheet. 
Table 3. Compared with experimental values, the average layer thickness and interlayer thickness of pyrophyllite $\left[\mathrm{Al}_{4} \mathrm{Si}_{8} \mathrm{O}_{20}(\mathrm{OH})_{4}\right]$ at $0 \mathrm{GPa}$ and that of given pressures.

\begin{tabular}{ccccccccccccc}
\hline $\begin{array}{c}\text { Pressure } \\
\text { (GPa) }\end{array}$ & \multicolumn{10}{c}{ Experiment [39] } & $\mathbf{1 0}$ & \multicolumn{10}{c}{ This Work } \\
\cline { 2 - 14 } & $\mathbf{0 . 0 0}$ & $\mathbf{0 . 0 0}$ & $\mathbf{0 . 8 5}$ & $\mathbf{1 . 8 8}$ & $\mathbf{2 . 7 7}$ & $\mathbf{4 . 0 5}$ & $\mathbf{5 . 0 7}$ & $\mathbf{6 . 6 2}$ & $\mathbf{8 . 2 3}$ & $\mathbf{9 . 8 9}$ & $\mathbf{1 1 . 7 3}$ & $\mathbf{1 3 . 8 7}$ \\
\hline$d_{I}(\AA)$ & 2.759 & 3.462 & 3.377 & 3.268 & 3.185 & 2.811 & 2.740 & 2.638 & 2.552 & 2.461 & 2.359 & 2.500 \\
$d_{T 1}(\AA)$ & 2.153 & 2.296 & 2.282 & 2.263 & 2.249 & 2.364 & 2.346 & 2.326 & 2.308 & 2.293 & 2.284 & 2.158 \\
$d_{O}(\AA)$ & 2.079 & 1.945 & 1.998 & 2.066 & 2.117 & 2.180 & 2.227 & 2.289 & 2.341 & 2.393 & 2.440 & 2.485 \\
$d_{T 2}(\AA)$ & 2.153 & 2.296 & 2.282 & 2.263 & 2.249 & 2.364 & 2.346 & 2.326 & 2.308 & 2.293 & 2.284 & 2.158 \\
\hline
\end{tabular}

\subsection{Effect of Pressure on the Mechanical Properties of Pyrophyllite}

Elastic property is the inherent property of the material, which represents the deformation extent of the material under the applied stress. For the triclinic system of pyrophyllite, 21 independent elastic stiffness constants [40] $C_{11}, C_{12}, C_{13}, C_{14}, C_{15}, C_{16}, C_{22}, C_{23}, C_{24}, C_{25}, C_{26}, C_{33}, C_{34}, C_{35}, C_{36}, C_{44}, C_{45}, C_{46}$, $C_{55}, C_{56}$, and $C_{66}$ are calculated by a Taylor expansion of the total energy of the system with respect to a small strain of the lattice primitive cell volume [41]. The strain amplitude $\delta$ is varied in steps of 0.01 from $\delta=-0.06$ to 0.06 . The derived results of the elastic constants under different pressure are listed in Table 4 . The calculated elastic constants at 0 GPa in Table 4 are in good agreement with other calculated results [42], meaning that our calculation work is high reliable. As listed in Table 4, it is observed that $C_{11}, C_{22}, C_{33}, C_{44}, C_{55}, C_{66}, C_{12}, C_{13}, C_{14}, C_{15}, C_{16}, C_{23}, C_{24}, C_{25}, C_{34}$, and $C_{35}$ increase with increasing pressure, while the other elastic stiffness constants decrease with increasing pressure. According to the mechanical stability criterion of crystal structure given by Cowley in 1976 [43], the mechanical stability of triclinic crystal system can be achieved if all the elastic constants $C_{i j}$ are satisfied by Born-Huang criteria. Combined with the calculation results of Table 4, it can be seen that the elastic constant of pyrophyllite crystal satisfies the mechanical stability condition under different pressures.

Table 4. The calculated elastic constants $C_{i j}(\mathrm{GPa})$ of pyrophyllite $\left[\mathrm{Al}_{4} \mathrm{Si}_{8} \mathrm{O}_{20}(\mathrm{OH})_{4}\right]$ at $0 \mathrm{GPa}$ compared with other calculated results and the calculated values under applied pressures.

\begin{tabular}{|c|c|c|c|c|c|c|c|c|c|c|c|c|}
\hline \multirow{2}{*}{ Pressure (GPa) } & \multirow{2}{*}{$\begin{array}{c}\text { Other Calculation [42] } \\
0.00\end{array}$} & \multicolumn{11}{|c|}{ This Work } \\
\hline & & 0.00 & 0.85 & 1.88 & 2.77 & 4.05 & 5.07 & 6.62 & 8.23 & 9.89 & 11.73 & 13.87 \\
\hline$C_{11}$ & 198.70 & 163.42 & 160.91 & 162.36 & 164.37 & 165.21 & 169.04 & 176.04 & 178.95 & 187.50 & 196.68 & 207.13 \\
\hline$C_{33}$ & 70.10 & 79.19 & 82.42 & 91.45 & 102.34 & 129.50 & 143.48 & 158.48 & 176.22 & 196.33 & 217.80 & 237.13 \\
\hline$C_{44}$ & 33.40 & 3.18 & 3.91 & 5.14 & 6.42 & 9.24 & 10.97 & 14.90 & 19.28 & 25.13 & 31.10 & 38.48 \\
\hline$C_{55}$ & 21.60 & 26.71 & 28.91 & 36.48 & 43.21 & 47.52 & 51.44 & 59.62 & 70.19 & 74.41 & 82.43 & 93.86 \\
\hline$C_{13}$ & 10.40 & -19.64 & -13.83 & -15.99 & -15.35 & -15.82 & -12.12 & -7.57 & -2.04 & 0.25 & 2.51 & 5.31 \\
\hline$C_{14}$ & / & 0.01 & -0.17 & -0.37 & 0.26 & 2.11 & 4.05 & 4.87 & 7.11 & 7.19 & 7.12 & 4.91 \\
\hline$C_{15}$ & / & -23.40 & -22.23 & -18.14 & -16.28 & -9.12 & -8.01 & -9.05 & -12.71 & -8.95 & -4.83 & -2.74 \\
\hline$C_{16}$ & l & 0.86 & 0.75 & 1.06 & 1.55 & 2.74 & 3.13 & 0.93 & -0.03 & -2.99 & -7.74 & 8.97 \\
\hline$C_{23}$ & 10.50 & -25.09 & -19.17 & -21.81 & -22.57 & -25.32 & -18.80 & -17.47 & -11.55 & -4.55 & 2.57 & 0.85 \\
\hline$C_{24}$ & / & 0.27 & -0.38 & -0.59 & -1.17 & -1.48 & 0.20 & 1.24 & 2.16 & 3.01 & 4.53 & 5.30 \\
\hline$C_{36}$ & I & -11.84 & -8.45 & -9.60 & -9.94 & -12.94 & -11.61 & -13.26 & -14.07 & -16.65 & -21.21 & -24.22 \\
\hline$C_{45}$ & I & -2.92 & -4.76 & -7.67 & -8.06 & -8.72 & -10.86 & -7.53 & -21.48 & -15.89 & -22.54 & -25.49 \\
\hline$C_{46}$ & I & -10.71 & -10.90 & -11.26 & -11.42 & -11.90 & -11.97 & -12.11 & -12.22 & -12.58 & -12.38 & -11.80 \\
\hline$C_{56}$ & I & -5.74 & -5.85 & -8.16 & -10.42 & -11.35 & -10.91 & -12.13 & -16.39 & -16.72 & -19.50 & -24.00 \\
\hline
\end{tabular}

To observe the trend of elastic constants, the curves of elastic constants of $C_{11}, C_{22}, C_{33}, C_{44}, C_{55}, C_{66}$, $C_{12}, C_{13}$, and $C_{23}$ varying with increasing pressure are drawn, as shown in Figure $3 \mathrm{a}-\mathrm{c}$. It is observed that $C_{11}, C_{22}$, and $C_{33}$ increase with increasing pressure, the elastic constant $C_{33}$ increases dramatically and the other two elastic constants are relatively gentle as shown in Figure 3a. The elastic constants of $C_{11}, C_{22}$, and $C_{33}$ increase by $26.75 \%, 6.10 \%$ and $199.44 \%$, respectively. The calculated longitudinal classic constants $C_{33}$ is less than $C_{11}$ before the pressure of $8.23 \mathrm{GPa}$ and less than $C_{22}$ before the 
pressure of $11.73 \mathrm{GPa}$, indicating that the $c$-axis anti-deformation ability is weaker than the $a$-axis and $b$-axis anti-deformation ability before the $8.23 \mathrm{GPa}$ and $11.73 \mathrm{GPa}$, respectively. The variation of $C_{33}$ is maximum from $79.19 \mathrm{GPa}$ to $237.13 \mathrm{GPa}$ and then becomes larger than $C_{11}$ and $C_{22}$ after the pressure of $11.73 \mathrm{GPa}$, which implies that pyrophyllite is less compressible under stress and then the increase of stiffness along $c$-axis is stronger. Inevitably, in the case of the relatively weak binding in $c$ direction and careful, but slightly imperfect, structural relaxation, the existing DFT is still not accurate enough to predict $C_{33}$ for weakly bonded sheet silicates. Furthermore, the elastic constants $C_{44}, C_{55}$, and $C_{66}$ are increased relatively gentle with increasing pressure as shown in Figure $3 b$, implying that pyrophyllite is stronger to resist shear distortion in the (100), (010), and (001) plane. The elastic constants of $C_{44}$, $C_{55}$, and $C_{66}$ increase from 3.18 GPa to $38.48 \mathrm{GPa}, 26.71 \mathrm{GPa}$ to $93.86 \mathrm{GPa}$, and 63.17 GPa to 78.31 GPa, respectively. Before the external pressure of $9.89 \mathrm{GPa}$, the elastic constants $C_{44}$ and $C_{55}$ are less than $C_{66}$, which implying that the shear deformation resistance of (001) is stronger than these of (100) and (010) plane. However, the elastic constant $C_{55}$ becomes larger than $C_{44}$ and $C_{66}$ after the pressure of 9.89 GPa, implying that the shear deformation resistance of (010) is stronger than these of (100) and (001) plane. Finally, the calculated values of $C_{12}, C_{13}$, and $C_{23}$ have a positive slope with increasing pressure from 21.66 GPa to $152.60 \mathrm{GPa},-19.64 \mathrm{GPa}$ to $5.31 \mathrm{GPa}$, and -25.09 GPa to 0.85 GPa as shown in Figure $3 c$, respectively. The values of $C_{12}$ increase significantly and are always larger than those of $C_{13}$ and $C_{23}$, which further implies that the interlayer van der Waals force of pyrophyllite crystals is less than that of interlayer bonding.

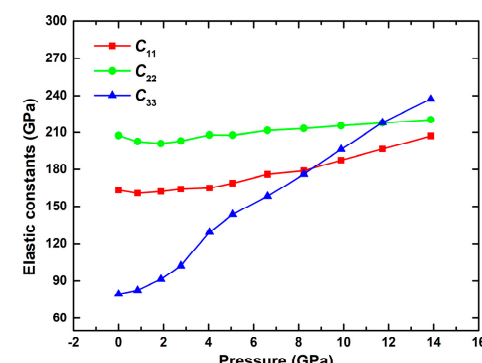

(a)

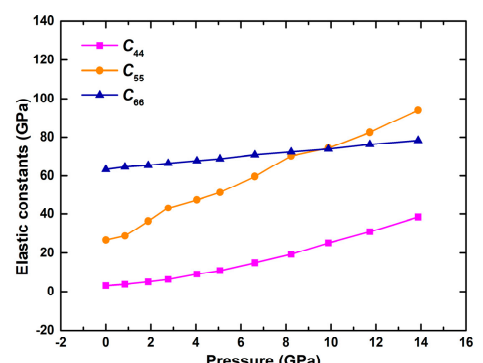

(b)

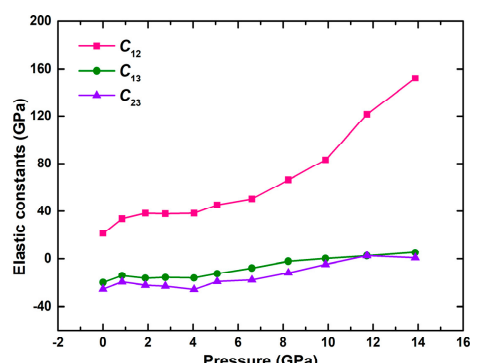

(c)

Figure 3. The calculated elastic constants $\left(C_{i j}\right)$ of pyrophyllite $\left[\mathrm{Al}_{4} \mathrm{Si}_{8} \mathrm{O}_{20}(\mathrm{OH})_{4}\right]$ under different pressures. (a) Calculated value of $C_{11}, C_{22}$ and $C_{33}$ under given pressures; (b) Calculated value of $C_{44}$, $C_{55}$ and $C_{66}$ under given pressures; (c) Calculated value of $C_{12}, C_{13}$, and $C_{23}$ under given pressures.

For elastic materials, elastic modulus can be used to reflect their ability to resist elastic deformation, which is one of the most important performance parameters of elastic materials. Fundamentally speaking, the elastic modulus reflects the bonding strength among atoms, ions, or molecules. The bulk modulus $(B)$, shear modulus $(G)$, and Young's modulus $(E)$ of pyrophyllite can be obtained from the calculated the elastic stiffness constants by using Viogt-Reuss-Hill (VRH) approximation, which are the mainly mechanical properties for a material. The calculation results of elastic parameters for pyrophyllite under different pressures are listed in Table 5. The elastic modulus of pyrophyllite crystals at 0 GPa calculated by LDA match the experimental values [28], which provides a guarantee for calculating the mechanical properties of pyrophyllite under pressure. 
Table 5. The calculated bulk modulus $(B)$, Young's modulus $(E)$, shear modulus $(G)$, Poisson's ratio $(\mu)$, Vickers hardness $\left(H_{v}\right)$, Cauchy pressure $\left(P_{c}\right)$, compression wave velocity $\left(V_{p}\right)$ and shear wave velocity $\left(V_{S}\right)$ of pyrophyllite $\left[\mathrm{Al}_{4} \mathrm{Si}_{8} \mathrm{O}_{20}(\mathrm{OH})_{4}\right]$ under different pressure, compared with experimental data.

\begin{tabular}{|c|c|c|c|c|c|c|c|c|c|c|c|c|}
\hline \multirow{2}{*}{ Pressure (GPa) } & \multirow{2}{*}{$\frac{\text { Experiment }[28]}{0.00}$} & \multicolumn{11}{|c|}{ This Work } \\
\hline & & 0.00 & 0.85 & 1.88 & 2.77 & 4.05 & 5.07 & 6.62 & 8.23 & 9.89 & 11.73 & 13.87 \\
\hline$B$ (GPa) & $14.8-37.5$ & 25.20 & 34.62 & 37.21 & 44.53 & 47.61 & 53.50 & 58.41 & 66.29 & 68.42 & 69.84 & 74.48 \\
\hline$E(\mathrm{GPa})$ & $6-53.6$ & 56.70 & 68.46 & 72.71 & 83.56 & 88.02 & 93.43 & 98.36 & 107.81 & 115.29 & 115.77 & 118.33 \\
\hline$G(\mathrm{GPa})$ & $18.2-21.3$ & 25.20 & 29.91 & 31.64 & 36.39 & 37.42 & 40.72 & 41.58 & 44.33 & 46.09 & 46.17 & 47.90 \\
\hline$\mu$ & $0.06-0.26$ & 0.12 & 0.16 & 0.17 & 0.18 & 0.19 & 0.21 & 0.21 & 0.21 & 0.22 & 0.22 & 0.24 \\
\hline$H_{v}(\mathrm{GPa})$ & I & 10.12 & 9.23 & 9.40 & 9.85 & 9.48 & 9.63 & 8.82 & 8.41 & 8.77 & 8.53 & 8.41 \\
\hline$P_{\mathrm{c}}(\mathrm{GPa})$ & l & 18.48 & 29.88 & 33.19 & 31.36 & 29.07 & 34.38 & 35.60 & 47.32 & 58.04 & 90.41 & 113.92 \\
\hline$V_{p}(\mathrm{~km} / \mathrm{s})$ & $3.78 \sim 4.91$ & 4.63 & 5.17 & 5.27 & 5.66 & 5.72 & 5.96 & 6.05 & 6.28 & 6.32 & 6.28 & 6.37 \\
\hline$V_{s}(\mathrm{~km} / \mathrm{s})$ & $2.58 \sim 2.79$ & 3.03 & 3.28 & 3.33 & 3.54 & 3.54 & 3.66 & 3.65 & 3.73 & 3.76 & 3.72 & 3.75 \\
\hline
\end{tabular}

To express the influence of pressure on the mechanical properties of pyrophyllite more intuitively, we draw the data in Table 5, as shown in Figure 4. It can be seen from Table 5 and Figure 4 that the elastoplasticity of pyrophyllite is affected by the applied pressure. The bulk modulus $(B)$ expresses the resistance to volume change with strain-stress and denotes the resistance to fracture and it is $25.20 \mathrm{GPa}$ at $0 \mathrm{GPa}$. When the pressure increases to $13.87 \mathrm{GPa}$, the bulk modulus $(B)$ increases to $74.48 \mathrm{GPa}$. In other words, the bulk modulus $(B)$ increase with the increase of applied pressure (see in Figure $4 \mathrm{a}$ ), which means that the incompressibility of pyrophyllite crystals increase during compression. The shear modulus $(G)$ describe an object's tendency to shear when acted upon by opposing forces. The Young's modulus $(E)$ can be used to describe the stiffness of a material, the smaller the Young's modulus $(E)$, the better the plasticity of the material is. During the whole pressurization process, the shear modulus $(G)$ (see in Figure 4c) increase from 25.20 GPa to $47.90 \mathrm{GPa}$, and the Young's modulus $(E)$ (see in Figure $4 \mathrm{~b}$ ) increase from $56.70 \mathrm{GPa}$ to $118.33 \mathrm{GPa}$, which indicate that the shear resistance and rigidity of the materials are enhanced during the pressing process.
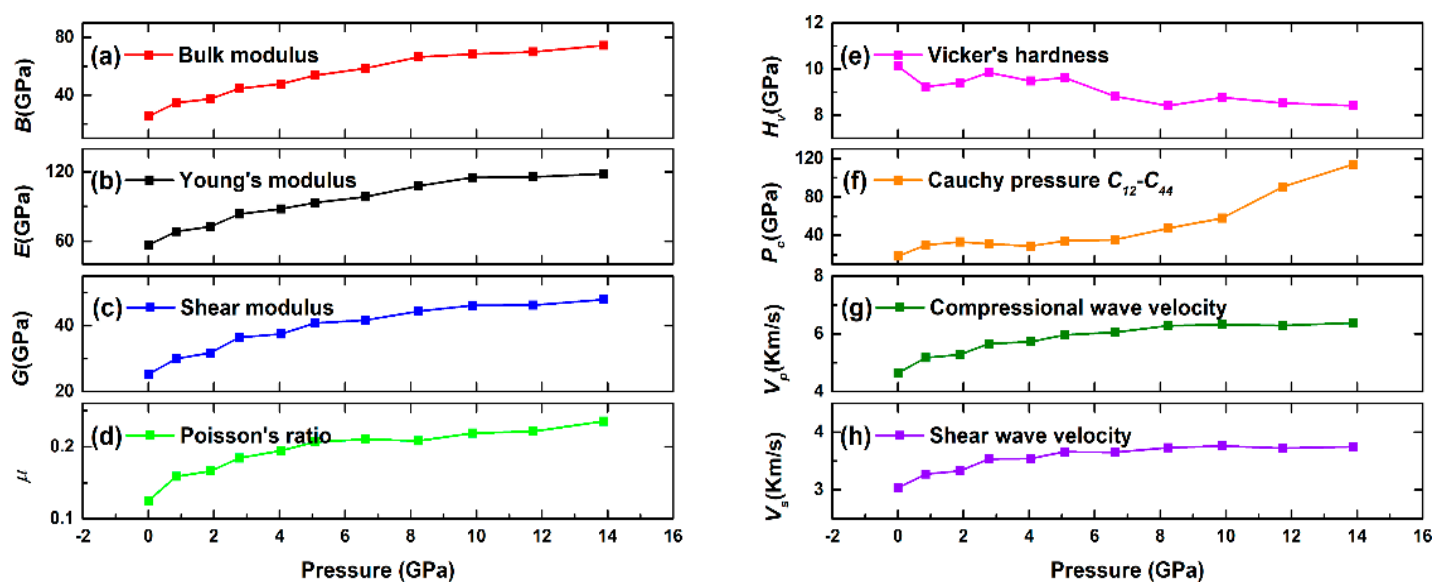

Figure 4. The calculated value of elastic modulus, Poisson's ratio, hardness and wave velocity of pyrophyllite $\left[\mathrm{Al}_{4} \mathrm{Si}_{8} \mathrm{O}_{20}(\mathrm{OH})_{4}\right]$ under different pressure. (a) Bulk modulus (B); (b) Young's modulus $(E)$;

(c) Shear modulus $(G)$; (d) Poisson's ratio $(\mu)$; (e) Vicker's hardness $\left(H_{v}\right)$; (f) Cauchy pressure $C_{12}-C 44$

$\left(P_{c}\right) ;(\mathrm{g})$ Compression wave velocity $\left(V_{p}\right) ;(\mathbf{h})$ Shear wave velocity $\left(V_{s}\right)$.

Moreover, the pressure dependence of the Poisson's ratio $(\mu)$, the Vickers hardness $\left(H_{v}\right)$, the Cauchy pressure $\left(P_{c}\right)$, the compression wave velocity $\left(V_{p}\right)$ and the shear wave velocity $\left(V_{s}\right)$ are further investigated.

The hardness of material is often expressed with Vickers hardness $\left(H_{v}\right)$, which is estimated by recently proposed empirical formula of $H_{v}=2\left(K^{2} G\right)^{0.583}-3$, where $K$ is Pugh's modulus ratio G/B. The calculated Vickers hardness $\left(H_{v}\right)$ is $10.12 \mathrm{GPa}$ for pyrophyllite at $0 \mathrm{GPa}$. Figure $4 \mathrm{e}$ shows that the Vicker's hardness $\left(H_{\mathcal{v}}\right)$ of pyrophyllite crystal decrease with the increase of pressure, i.e., the hardening 
effect of pyrophyllite is gradually weakening. The reason for this phenomenon is that with the decrease of crystal volume, the distance between atoms layer and the atoms decrease, the van der Waals force between the layers and the bonding strength between the atoms in the crystal layer increase, and the stress required to resist further elastic deformation increase. The Cauchy pressure $\left(C_{12}-C_{44}\right)$ can accurately predict the brittle ductile behavior of materials. The calculated value of Cauchy pressure of pyrophyllite crystal is $18.48 \mathrm{GPa}$ at $0 \mathrm{GPa}$ and it increases obviously with the increase of pressure (see in Figure 4f). This phenomenon shows that the toughness of pyrophyllite is improved. The Poisson's ratio $(\mu)$ is an elastic parameter that reflects the stability of a crystal against shear stress and an indicator of bonding nature. The calculated for the Poisson's ratio $(\mu)$ of pyrophyllite is 0.12 , implying that the strong covalent feature of chemical bonding, because it is less than the critical value of 0.27 . The larger the Poisson's ratio $(\mu)$ is, the greater the toughness of the material is. It can be seen from Figure $4 \mathrm{~d}$ that with the gradual increase of pressure from $0 \mathrm{GPa}$ to $13.87 \mathrm{GPa}$, the Poisson's ratio $(\mu)$ of pyrophyllite increases from 0.12 to 0.24 , i.e., the extensibility of pyrophyllite increases, which fully shows that the plasticity of pyrophyllite has been improved. As shown in Table 5 , the obtained compression wave velocity $\left(V_{p}\right)$ and shear wave velocity $\left(V_{s}\right)$ are $4.63 \mathrm{~km} / \mathrm{s}$ and $3.03 \mathrm{~km} / \mathrm{s}$, respectively. The velocity of elastic wave is related to density. The higher the density of material is, the faster the velocity of elastic wave is. In addition, with the increase of the pressure, the compression wave velocity $\left(V_{p}\right)$ increases, and the change trend is consistent with the elastic modulus. The influence of compression pressure on the shear wave velocity $\left(V_{s}\right)$ is smaller than that of the compression wave velocity $\left(\mathrm{V}_{p}\right)$.

\subsection{Effect of Pressure on the Electronic Properties of Pyrophyllite}

To deeply understand the effect of pressure on the electronic properties in pyrophyllite crystal, the energy band structure, the total density of states, the partial density of wave states and differential charge density of pyrophyllite at $0 \mathrm{GPa}$ and $13.87 \mathrm{GPa}$ are further analyzed, respectively.

The band gap of the material reflects its conductive properties. As we all know, the band gap of a semi-conductor is about $0.1-2 \mathrm{eV}$, and that of an insulator is more than $3 \mathrm{eV}$. Figure 5 shows the energy band structure of pyrophyllite crystal. The transverse axis of the band structure diagram is the high-symmetry point in the Brillouin zone, which includes $\Gamma(0.0,0.0,0.0), B(0.5,0.0,0.0)$, $F(0.0,0.5,0.0)$ and $G(0.0,0.0,0.5)$. The band structure of pyrophyllite along high-symmetry lines in the Brillouin zone at ground state ( $0 \mathrm{GPa})$ and high pressure $(13.87 \mathrm{GPa})$ are plotted in Figure 5 . Obviously, the energy band structure of pyrophyllite is relatively flat, the Fermi energy level is located at the valence-band maximum (VBM). The VBM of pyrophyllite at $0 \mathrm{GPa}$ is located at $\Gamma(0.0,0.0,0.0)$ in Brillouin zone, while the VBM under high pressure of $13.87 \mathrm{GPa}$ is located at $\mathrm{F}(0.0,0.5,0.0)$ in Brillouin zone. The conduction-band minimum $(\mathrm{CBM})$ of both states is located at $\Gamma(0.0,0.0,0.0)$ in Brillouin zone. It can be found that pyrophyllite at $0 \mathrm{GPa}$ has a direct band gap, and the transition of electrons to the conduction band only needs to absorb energy. Pyrophyllite at 13.87 GPa has an indirect band gap; therefore, forming a half-full band requires not only the absorption of energy, but also the change of momentum. The band gap of pyrophyllite is $5.42 \mathrm{eV}$ at $0 \mathrm{GPa}$, and that of pyrophyllite under the pressure of $13.87 \mathrm{GPa}$ is $5.86 \mathrm{eV}$. That is to say, the band gap of pyrophyllite is widened by pressure. The pressure state makes it more difficult for the electron to obtain enough energy to transfer from the valence band to the conduction band. Pyrophyllite maintains typical insulator characteristics within the pressure from $0 \mathrm{GPa}$ to13.87 GPa. As we all know, the insulation is one of the factors that must be possessed by the sealed pressure-transmission medium. Therefore, this electronic structure characteristic of pyrophyllite partly proves the reliability of pyrophyllite as the sealing pressure-transmission medium. 


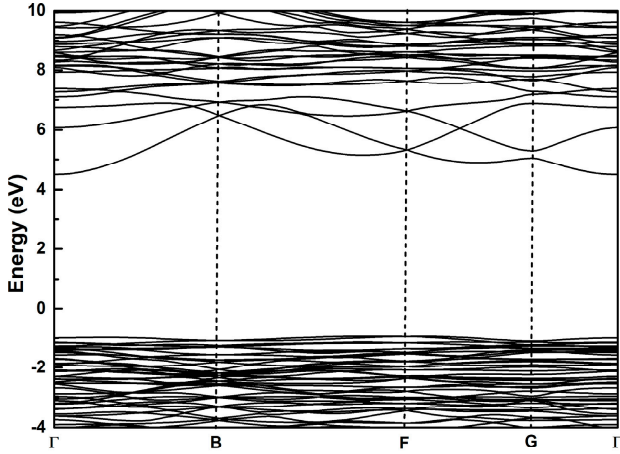

(a) $0 \mathrm{GPa}$

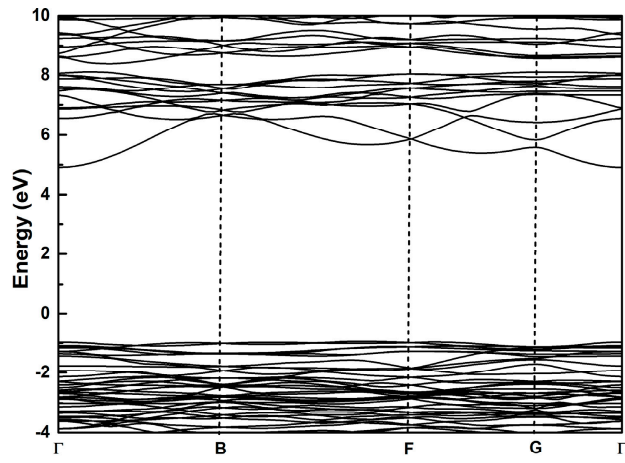

(b) $13.87 \mathrm{GPa}$

Figure 5. The band structure of pyrophyllite $\left[\mathrm{Al}_{4} \mathrm{Si}_{8} \mathrm{O}_{20}(\mathrm{OH})_{4}\right]$ along high-symmetry lines in the Brillouin zone. (a) The band structure at $0 \mathrm{GPa}$; (b) The band structure at $13.87 \mathrm{GPa}$.

The density of states (DOS) can reflect the distribution of electrons in each orbital and the interaction between atoms. Therefore, DOS can reveal the information of chemical bonds as a visual result of band structure. In Figure 6, we draw the total state density (DOS) and projected state density (PDOS) of pyrophyllite at $0 \mathrm{GPa}$ and $13.87 \mathrm{GPa}$ to understand the effect of pressure environment on the bonding and electronic structure of pyrophyllite. Fermi energy $E_{F}$ is set to $0 \mathrm{eV}$. The PDOS of $\mathrm{O}$ (apical), $\mathrm{O}$ (ring) and $\mathrm{O}$ (inner) are drawn in Figure 6 because of their discrepancies in symmetry and position. It is found that the PDOS trends of different kinds of oxygen atoms are similar. The reason for this phenomenon may be that the high ionic properties of oxygen atoms lead to large charge transfer from $\mathrm{Al} 3 p, \mathrm{Si} 3 p$, and $\mathrm{H} 1 s$ states to $\mathrm{O} 2 p$ states. It can also be seen from Figure 6 that the $\mathrm{O} 2 p$ state is a significant part of the valence band in the wide energy range $\left(-10 \mathrm{eV}<\mathrm{E}<\mathrm{E}_{F}\right)$. There are some residual charges in the $\mathrm{Al} 3 s / 3 p$ and $\mathrm{Si} 3 s / 3 p$ states, which means that there are obvious covalent components in the chemical bonds of $\mathrm{Al}-\mathrm{O}$ and $\mathrm{Si}-\mathrm{O}$ in pyrophyllite. The peak value of DOS of pyrophyllite is sharp, which indicates that pyrophyllite has strong localization, which makes the crystal have excellent properties in hardness, chemical inertness, and thermal stability. It can also be seen from Figure 6 that the pressure makes the valence band of pyrophyllite move to the left and the conduction band to the right, i.e., the pressure makes the band gap of pyrophyllite wider and the covalent bond characteristics strengthen. From the PDOS curve of pyrophyllite, it can be seen that pressure has tiny effect on the electron density of pyrophyllite.

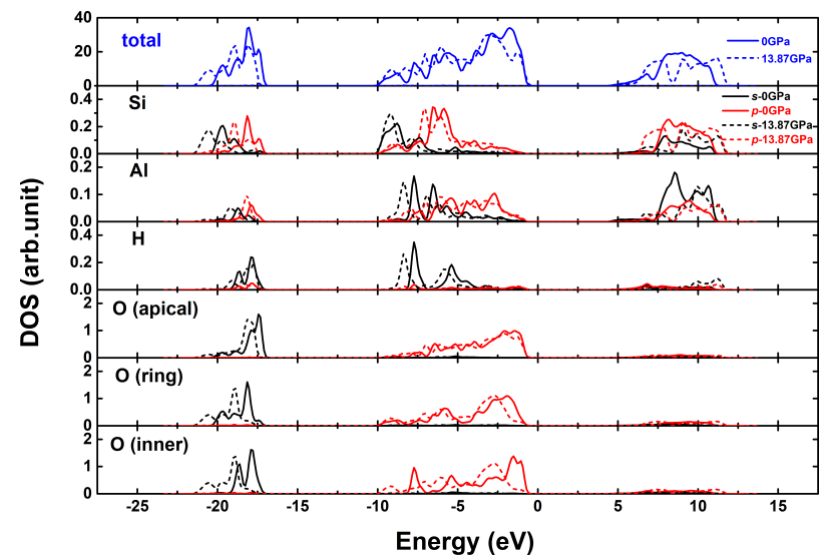

Figure 6. The total and partial density of states of pyrophyllite $\left[\mathrm{Al}_{4} \mathrm{Si}_{8} \mathrm{O}_{20}(\mathrm{OH})_{4}\right]$ at $0 \mathrm{GPa}$ and $13.87 \mathrm{GPa}$. The blue solid curve-the total density of states at $0 \mathrm{GPa}$; the blue short dash curve-the total density of states at $13.87 \mathrm{GPa}$; the black solid curve-the partial density of $s$ states at $0 \mathrm{GPa}$; the red solid curve-the partial density of $p$ states at $0 \mathrm{GPa}$; the black short dash curve-the partial density of $s$ states at $13.87 \mathrm{GPa}$; the red short dash curve-the partial density of $p$ states at $13.87 \mathrm{GPa}$. 
To understand the bonding characteristics of atoms in pyrophyllite system more intuitively, we draw the charge density diagram of the plane in which the Al-O-Si is in pyrophyllite crystal as Figure 7. It can be seen from the diagram that the covalent bond characteristics of $\mathrm{Si}-\mathrm{O}$ bonds are more obvious, while the Al-O bonds are mainly characterized by ionic bonds and had a small amount of covalency. The main reason is that the difference of electronegativity leads to the obvious charge transfer between the $\mathrm{Al}$ atom and the surrounding $\mathrm{O}$ atom. It is also confirmed that $\mathrm{Al}$ ions in pyrophyllite are easier to be replaced by some low valence ions than $\mathrm{Si}$ ions. With the increase of pressure, the degree of electron density overlap between $\mathrm{O}$ atom and $\mathrm{Al}(\mathrm{Si})$ atom is higher, indicating that pressure in a certain range (from $0 \mathrm{GPa}$ to $13.87 \mathrm{GPa}$ ) makes the covalent bond characteristic stronger. This is consistent with the results of the densities of atomic states of $\mathrm{Al}, \mathrm{O}$, and $\mathrm{Si}$ in pyrophyllite.

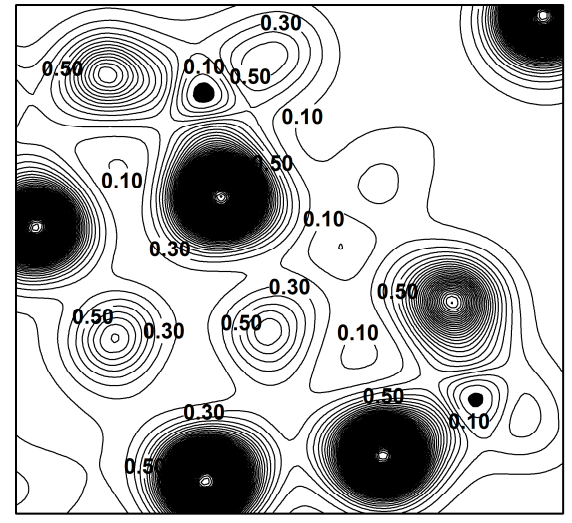

(a) OGPa

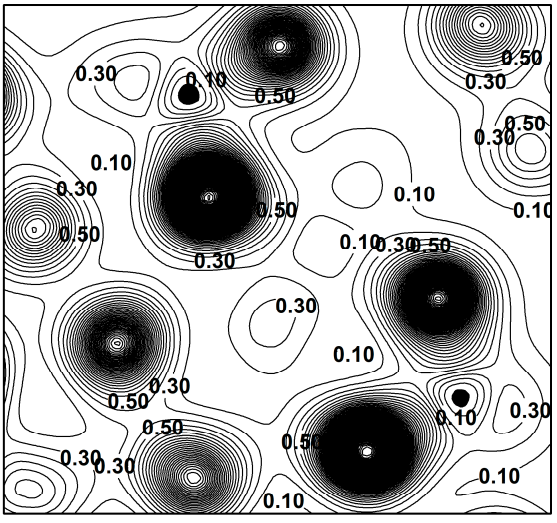

(b) $13.87 \mathrm{GPa}$

Figure 7. The charge density distribution of the Al-O-Si plane in pyrophyllite $\left[\mathrm{Al}_{4} \mathrm{Si}_{8} \mathrm{O}_{20}(\mathrm{OH})_{4}\right]$. (a) The charge density distribution of the Al-O-Si plane at $0 \mathrm{GPa}$; (b) The charge density distribution of the Al-O-Si plane at $13.87 \mathrm{GPa}$.

\section{Conclusions}

Pyrophyllite is a mineral with less geological exploration and lower mineralogical research degree in China. Due to the low use of pyrophyllite resources and the rapid development of superhard material industry in China, we need to pay more attention to the physical and mechanical research of pyrophyllite. In the present paper, the mechanical, electronic, and structural characteristics of pyrophyllite crystal under high pressure (from $0 \mathrm{GPa}$ to $13.87 \mathrm{GPa}$ ) are calculated in detail by LDA method based on DFT. The main conclusions are summarized as follows:

(1) At zero pressure, the calculated structural parameters of pyrophyllite in this paper are in good accord with the existing experimental results. With increasing pressure, the volume, bond lengths, interlayer thickness, and layer thickness of pyrophyllite decrease gradually. In particular, the cation-anion bond along the $c$-axis in pyrophyllite is weaker than the cation-anion bond along the $a-b$ plane, which indicates the deformation observed in pyrophyllite is mostly along the $c$-axis.

(2) At different pressures, the calculated elastic constants of pyrophyllite satisfy with Born-Huang criteria, indicating that triclinic pyrophyllite is mechanical stability. The elastic constants $C_{11}$, $C_{22}, C_{33}, C_{44}, C_{55}, C_{66}, C_{12}, C_{13}, C_{14}, C_{15}, C_{16}, C_{23}, C_{24}, C_{25}, C_{34}$, and $C_{35}$ increase with increasing pressure, while the other elastic stiffness constants decrease with increasing pressure. Meanwhile, the calculated bulk modulus, shear modulus, Young modulus, Poisson's ratio, Pugh's modulus, Cauchy pressure increase with increasing pressure, indicating the elastic mechanics and the ductility of pyrophyllite is significantly improved.

(3) The DOS, charge density distribution and band structure results show that pyrophyllite has covalent feature and is an insulator at zero pressure. With the increase of pressure from $0 \mathrm{GPa}$ to $13.87 \mathrm{GPa}$, the calculated electronic quantity changes slightly, indicating that the pressure has a little effect on the electronic properties of pyrophyllite. At $13.87 \mathrm{GPa}$, pyrophyllite still 
maintains the typical insulation, which partly proves the reliability of pyrophyllite as a sealed pressure-transmission medium from the perspective of electronic structure., and pyrophyllite still has good stability under high pressure

Author Contributions: Conceptualization and methodology, J.Z., X.Q., M.H.; software, J.Z.; validation, formal analysis, data curation, and writing, X.Q., J.Z.; investigation, X.Q., J.W.; funding acquisition, M.H. All authors have read and agreed to the published version of the manuscript.

Funding: This research was funded by the National Natural Science Foundation of China, grant number 41702317 and 51574296.

Acknowledgments: The author is grateful to the Chinese Scholarship Council and the University of Adelaide for providing an opportunity to conduct this research as a joint Ph.D. Student.

Conflicts of Interest: The authors declare no conflict of interest.

\section{References}

1. Zhang, W. Application progress of pyrophyllite in China. Miner. Rock 2016, 36, 15-28. (In Chinese)

2. Greathouse, J.A.; Cygan, R.T. Chapter 3-Molecular Simulation of Clay Minerals. In Developments in Clay Science, 3rd ed.; Bergaya, F., Lagaly, G., Eds.; Handbook of Clay Science; Elsevier: Amsterdam, The Netherlands, 2013; pp. 405-423.

3. Li, D.M.; Liu, G.Z.; Zhou, J.X. Water promoted phase transition of pyrophyllite under ultra high pressure and high temperature and its influence on technical application. Sci. Bull. 1978, 481-485. (In Chinese)

4. Du, P.X.; Yuan, P. Studies and Applications of Pyrophyllite in Key Mineral Material Areas Such as Superhard Materials. Conserv. Util. Miner. Resour. 2019, 39, 87-92. (In Chinese)

5. Deng, W.L.; Deng, F.M.; Ma, X.D.; Xu, C.Y.; Zhao, J. Synchroteon radiation X-ray diffraction analysis of pyrophyllite under high-pressure. J. Min. Sci. Technol. 2019, 4, 254-260.

6. Ulian, G.; Valdrè, G. Structural, vibrational and thermophysical properties of pyrophyllite by semi-empirical density functional modelling. Phys. Chem. Miner. 2015, 42, 609-627. [CrossRef]

7. Berthonneau, J.; Hoover, C.G.; Granby, O.; Baronnet, M.; Pellenq, R.J.M.; Ulm, F.J. Crystal-chemistry control of the mechanical properties of 2:1 clay minerals. Appl. Clay Sci. 2017, 143, 387-398. [CrossRef]

8. Sachse, W.; Ruoff, A.L. Elastic moduli of precompressed pyrophyllite used in ultrahigh, ressure research. J. Appl. Phys. 1975, 46, 3725-3730. [CrossRef]

9. Zhang, G.P.; Wei, Z.G.; Ferrell, R.E.; Guggenheim, S.; Cygan, R.T.; Luo, J. Evaluation of the elasticity normal to the basal plane of non-expandable 2:1 phyllosilicate minerals by nanoindentation. Am. Mineral. 2010, 95, 863-869. [CrossRef]

10. Cheng, Q.L.; Sondergeld, C.; Rai, C. Experimental study of rock strength anisotropy and elastic modulus anisotropy. In SEG Technical Program Expanded Abstracts 2013; SEG: Houston, TX, USA, 2013; pp. 362-367.

11. LiBalan, E.; Pietrucci, F.; Gervais, C.; Blanchard, M.; Schott, J.; Gaillardet, J. First-principles study of boron speciation in kaolinite and aragonite. Geochim. Cosmochim. Acta 2016, 193, 119-131.

12. Weck, P.F.; Kim, E.; Jové-Colón, C.F. Relationship between crystal structure and thermo-mechanical properties of kaolinite clay: Beyond standard density functional theory. Dalton Trans. 2015, 44, 12550-12560. [CrossRef]

13. Fang, Z.J.; Zhai, X.S.; Li, Z.L.; Pan, R.J.; Mo, M. Pressure dependence of the electronic structure in kaolinite: A first-principles study. Mod. Phys. Lett. B 2017, 31, 1750194. [CrossRef]

14. Molina-Montes, E.; Donadio, D.; Herna, N.L.A.; Sainz, C.I.; Parrinello, M. DFT research on the dehydroxylation reaction of pyrophyllite1. first-principle molecular dynamics simulations. J. Phys. Chem. B 2008, 112, 7051-7060. [CrossRef] [PubMed]

15. Zhao, J.; He, M.C.; Hu, X.X.; Gao, W. Density functional theory investigation of carbon monoxide adsorption on the kaolinite (001) surface. Chin. Phys. B 2017, 26, 079101. [CrossRef]

16. Gatta, G.D.; Lotti, P.; Merlini, M.; Liermann, H.P.; Lausi, A.; Valdrè, G.; Pavese, A. Elastic behaviour and phase stability of pyrophyllite and talc at high pressure and temperature. Phys. Chem. Miner. 2014, 42, 309-318. [CrossRef]

17. Bridgeman, C.H. Ab-initio total energy study of uncharged 2:1 clays and their interaction with water. Mol. Phys. 1996, 89, 879-888. [CrossRef] 
18. Refson, K.; Park, S.H.; Sposito, G. Ab Initio Computational Crystallography of 2:1 Clay Minerals: 1. Pyrophyllite-1Tc. J. Phys. Chem. B 2003, 107, 13376-13383. [CrossRef]

19. Katti, D.R.; Schmidt, S.R.; Ghosh, P.; Katti, K.S. Modeling the response of pyrophyllite interlayer to applied stress using steered molecular dynamics. Clays Clay Miner. 2005, 53, 171-178. [CrossRef]

20. Militzer, B.; Wenk, H.R.; Stackhouse, S.; Stixrude, L. First-principles calculation of the elastic moduli of sheet silicates and their application to shale anisotropy. Am. Mineral. 2011, 96, 125-137. [CrossRef]

21. Parr, R.G.; Yang, W.T. Density-Functional Theory of Atoms and Molecules; Oxford University Press: Oxford, UK, 1989.

22. Bucko, T.; Hafner, J.; Lebegue, S.; Angyan, J.G. Improved description of the structure of molecular and layered crystals: Ab initio DFT calculations with van der Waals corrections. J. Phys. Chem. A 2010, 114, 11814. [CrossRef]

23. Blchl, P.E. Projector Agmented-Wave Method. Phys. Rev. B 1994, 50, 17953-17979. [CrossRef]

24. Monkhorst, H.J. Special points for Brillouin-zone integrations. Phys. Rev. B Condens. Matter 1976, 16, 1748-1749. [CrossRef]

25. Pawley, A.; Clark, S.; Chinnery, N. Equation of state measurements of chlorite, pyrophyllite, and talc. Am. Mineral. 2002, 87, 1172-1182. [CrossRef]

26. Bruno, M.; Prencipe, M.; Giovanni, V. Ab initio quantum mechanical modeling of pyrophyllite $\left[\mathrm{Al}_{2} \mathrm{Si}_{4} \mathrm{O}_{10}(\mathrm{OH})_{2}\right]$ and talc $\left[\mathrm{Mg}_{3} \mathrm{Si}_{4} \mathrm{O}_{10}(\mathrm{OH})_{2}\right]$ surfaces. Phys. Chem. Miner. 2006, 33, 63-71. [CrossRef]

27. Aleksandrov, K.; Prodaivoda, G. Elastic properties of minerals. Crystallogr. Rep. 1993, 38, 698-709.

28. Zhao, J.; He, M.C. Theoretical study of heavy metal Cd, Cu, Hg, and $\mathrm{Ni}(\mathrm{II})$ adsorption on the kaolinite(001) surface. Appl. Surf. Sci. 2014, 317, 718-723. [CrossRef]

29. Voigt, W. Lehrbuch der Kristallphysik; Teubner: Leipzig, Germany, 1928.

30. Reuss, A. Berechnung der Fließgrenze von Mischkristallen auf Grund der Plastizitätsbedingung für Einkristalle. ZAMM J. Appl. Math. Mech. 1929, 9, 49-58. [CrossRef]

31. Hill, R. The Elastic Behaviour of a Crystalline Aggregate. Proc. Phys. Soc. Sect. A 1952, 65, 349-354. [CrossRef]

32. Brindley, G.W. Phyllosilicate. In Mineralogy; Springer: New York, NY, USA, 1981.

33. Kogure, T. Stacking structures in pyrophyllite revealed by high-resolution transmission electron microscopy (hrtem). Am. Mineral. 2006, 91, 1293-1299. [CrossRef]

34. Hendricks, S.B. Lattice Structure of Clay Minerals and Some Properties of Clays. J. Geol. 1942, 50, $276-290$. [CrossRef]

35. Rayner, J.; Brown, G. Structure of pyrophyllite. Clays Clay Miner. 1966, 25, 73-84. [CrossRef]

36. Giese, R. Hydroxyl orientation in pyrophyllite. Nature 1973, 241, 151. [CrossRef]

37. Churakov, S.V. Ab Initio Study of Sorption on Pyrophyllite: Structure and Acidity of the Edge Sites. J. Phys. Chem. B 2006, 110, 4135-4146. [CrossRef] [PubMed]

38. Drits, V.A.; Guggenheim, S.; Zviagina, B.B.; Kogure, T. Structures of the 2:1 Layers of Pyrophyllite and Talc. Clays Clay Miner. 2012, 60, 574-587. [CrossRef]

39. Lee, J.H.; Guggenheim, S. Single crystal X-ray refinement of pyrophyllite-1Tc. Am. Mineral. 1981, 66, 350-357.

40. Benazzouz, B.K.; Zaoui, A. Phase diagram of kaolinite from Molecular Dynamics calculations. Phys. B Condens. Matter 2012, 407, 2462-2470. [CrossRef]

41. Zhao, J.; Qin, X.Z.; Wang, J.M.; He, M.C. Effect of $\mathrm{Mg}(\mathrm{II})$ and $\mathrm{Na}(\mathrm{I})$ Doping on the Electronic Structure and Mechanical Properties of Kaolinite. Minerals 2020, 10, 368. [CrossRef]

42. Zartman, G.D.; Liu, H.; Akdim, B.; Pachter, R.; Heinz, H. Nanoscale Tensile, Shear, and Failure Properties of Layered Silicates as a Function of Cation Density and Stress. J. Phys. Chem. C 2010, 114, 1763-1772. [CrossRef]

43. Cowley, R.A. Critical Scattering from Structural Phase Transitions Associated with a Homogeneous Deformation of the Crystal. In Proceedings of the Conference on Neutron Scattering, Gatlinburg, TN, USA, 6-10 June 1976.

(C) 2020 by the authors. Licensee MDPI, Basel, Switzerland. This article is an open access article distributed under the terms and conditions of the Creative Commons Attribution (CC BY) license (http://creativecommons.org/licenses/by/4.0/). 